\title{
Protective effect of the ethanol extract of Magnolia officinalis and 4- $O$-methylhonokiol on scopolamine-induced memory impairment and the inhibition of acetylcholinesterase activity
}

\author{
Yong Kyung Lee · Dong Yeon Yuk · Tae Il Kim • \\ Young Heui Kim $\cdot$ Kyoung Tae Kim $\cdot$ Ki Ho Kim $\cdot$ \\ Beom Jun Lee $\cdot$ Sang-Yoon Nam $\cdot$ Jin Tae Hong
}

Received: 25 August 2008/Accepted: 9 March 2009/Published online: 4 April 2009

(c) The Author(s) 2009. This article is published with open access at Springerlink.com

\begin{abstract}
Magnolol, honokiol, and obovatol are wellknown bioactive constituents of the bark of Magnolia offcinalis and have been used as traditional Chinese medicines for the treatment of neurosis, anxiety, and stroke. We recently isolated novel active compound (named 4-Omethylhonokiol) from the ethanol extract of Magnolia offcinalis. The present study aimed to test two different doses of ethanol extracts of Magnolia officinalis $(5$ and $10 \mathrm{mg} / \mathrm{kg} /$ mouse, p.o., 1 week) and 4- $O$-methylhonokiol ( 0.75 and $1.5 \mathrm{mg} / \mathrm{kg} / \mathrm{mouse}$, p.o., 1 week) administered for 7 days on memory impairment induced by scopolamine $(1 \mathrm{mg} / \mathrm{kg}$ body weight i.p.) in mice. Memory and learning were evaluated using the Morris water maze and the step-down avoidance test. Both the ethanol extract of Magnolia officinalis and 4-O-methylhonokiol prevented memory impairment induced by scopolamine in a dose-dependent manner. The ethanol extract of Magnolia officinalis and 4-O-methylhonokiol also dose-dependently attenuated the scopolamine-induced increase of acetylcholinesterase (AChE) activity in the cortex and hippocampus of mice, and
\end{abstract}

Y. K. Lee · D. Y. Yuk · T. I. Kim · J. T. Hong ( $ه)$

College of Pharmacy,

Chungbuk National University,

12, Gaesin-dong, Heungduk-gu, Cheongju,

Chungbuk 361-763, Korea

e-mail: jinthong@chungbuk.ac.kr

B. J. Lee · S.-Y. Nam · J. T. Hong

College of Veterinary Medicine,

Chungbuk National University,

12, Gaesin-dong, Heungduk-gu, Cheongju,

Chungbuk 361-763, Korea

Y. H. Kim · K. T. Kim · K. H. Kim

R\&D Center, Bioland Ltd., Songjeong, Byongchon,

Cheonan-si, Chungnam 330-863, Korea inhibited AChE activity in vitro with $\mathrm{IC}_{50}(12 \mathrm{nM})$. This study, therefore, suggests that the ethanol extract of Magnolia officinalis and its major ingredient, 4-O-methylhonokiol, may be useful for the prevention of the development or progression of $\mathrm{AD}$.

Keywords Ethanol extract of Magnolia officinalis . 4-O-methylhonokiol · Alzheimer's disease · Memory · Acetylcholinesterase

\section{Introduction}

Alzheimer's disease (AD), a type of progressive dementia, is a neurodegenerative disorder characterized by a progressive cognitive decline resulting from selective neuronal dysfunction, synaptic loss, and neuronal cell death [1-5]. Numerous medications are undergoing testing for the treatment of the dementia associated with $\mathrm{AD}$, however, there is no known cure for AD. Studies of patients with $A D$ revealed the depleted levels of acetylcholine in an $\mathrm{AD}$ patient's brain. Centrally acting cholinergic drugs have been reported to increase the regional cerebral blood flow of acetylcholine in the brain regions affected by AD [6]. Thus, the maintaining of the acetylcholine level in the brain is important for the cure of AD patients. One method for this is blocking the activity of acetylcholinesterase (AChE), the enzyme-degrading acetylcholine. The cholinesterase inhibitors (AChEI) donepezil hydrochloride, galantamine hydrobromide, and rivastigmine tartrate are the current approved drugs for the treatment of AD patients [7]. However, AChEI presents some limitations, such as their short half-lives and excessive side effects caused by the activation of peripheral cholinergic systems, as well as hepatotoxicity, which is the most frequent and important 
side effect of these drug therapies [8-11]. For this reason, alternative and complementary therapies need to be developed. Thus, novel AChE inhibitors from plant sources could be valuable alternatives in the context of the treatment of AD. Several studies have shown the neuroprotective and/or cognition-enhancing properties of natural products and their components using different animal models [12-18].

Magnolol, honokiol, and obovatol are well-known bioactive constituents of the bark of Magnolia officinalis. Magnolol and honokiol have been known to have various pharmacological activities, such as anti-inflammatory, antibacterial, and anti-allergic activities, and have also been used as traditional Chinese medicines for the treatment of neurosis, anxiety, stroke, fever, and headache [19]. Honokiol was known to promote a potassium-induced release of acetylcholine in a rat hippocampal slice [20] and to enhance neurite sprouting [21]. In addition, magnolol and honokiol exhibited an $\mathrm{AChE}$ inhibitory property in rat spleen microsomes and human polymorphonuclear leukocytes [22]. Moreover, we recently found that obovatol has high anti-anxiety activity [23] and anti-AChE activity (unpublished data). Among various constituents of the ethanol extract of Magnolia officinalis, we have isolated a major compound (40-50\%) identified as 4-O-methylhonokiol that has not demonstrated any pharmacological activities. Therefore, in this study, we investigated whether the ethanol extract of Magnolia officinalis and 4-O-methylhonokiol could inhibit the memory impairment induced by scopolamine through the inhibition of AChE.

\section{Materials and methods}

Animals

Male ICR mice weighing 25-30 g (Samtako, Gyeonggi-do, Korea) were maintained in accordance with the guidelines of the National Institute of Toxicological Research of the Korea Food and Drug Administration for the care and use of laboratory animals. Animals were housed three per cage, allowed access to water and food ad libitum, and maintained on a 12 -h light/dark cycle regulated at $23^{\circ} \mathrm{C}$ room temperature. The experiments were performed at least 1 week after their arrival in individual home cages. Sixty mice were used for the water maze test and another 60 mice were used for the step-through test. Ten mice per group were used for each of the memory tests; Group 1: control, Group 2: scopolamine-treated, Group 3: scopolamine with $5 \mathrm{mg} / \mathrm{kg}$ ethanol extract, Group 4: scopolamine with $10 \mathrm{mg} / \mathrm{kg}$ ethanol extract, Group 5: scopolamine with $0.75 \mathrm{mg} / \mathrm{kg}$ 4-O-methylhonokiol, Group 6: scopolamine with $1.5 \mathrm{mg} / \mathrm{kg} 4-O$-methylhonokiol. The mice used for the water maze test were used for the assay of AChE activity.
Materials

The bark of Magnolia officinalis Rehd. et Wils. was dried in the shade at room temperature and stored in a dark, cold room until use. The air-dried bark of Magnolia officinalis Rehd. et Wils. $(3 \mathrm{~kg})$ was cut into pieces and extracted twice with $95 \%(\mathrm{v} / \mathrm{v})$ ethanol (four times as much as the weight of the dried plants) for 3 days at room temperature. After filtration through the 400-mesh filter cloth, the filtrate was filtered again through filter paper (Whatman Grade No. 5 ) and concentrated under reduced pressure. The combined extract $(450 \mathrm{~g})$ was suspended in $\mathrm{H}_{2} \mathrm{O}$ and the aqueous suspension was extracted with $n$-hexane, ethyl acetate, and $n$-BuOH, respectively. The $n$-hexane layer was evaporated to dryness to give a residue $(70 \mathrm{~g})$, which was chromatographed on silica gel with $n$-hexane:ethyl acetate $(9: 1)$ gradient to yield a crude fraction that included 4-O-methylhonokiol. This fraction was repeatedly purified by silica gel chromatography using $n$-hexane:ethyl acetate as the eluent to obtain pure 4-O-methylhonokiol (Fig. 1a). 4-Omethylhonokiol was identified by ${ }^{1} \mathrm{H}-\mathrm{NMR}$ and ${ }^{13} \mathrm{C}-\mathrm{NMR}$. The results of the NMR data are as follows and are in agreement with previously published data [24]. ${ }^{1} \mathrm{H}-\mathrm{NMR}$ $\left(400 \mathrm{MHz}, \mathrm{CDCl}_{3}\right): \delta 3.36(2 \mathrm{H}, \mathrm{d}, J=7 \mathrm{~Hz}, \mathrm{H}-7), 3.44$ $\left(2 \mathrm{H}, \mathrm{d}, J=7 \mathrm{~Hz}, 7^{\prime}-\mathrm{H}\right), 3.89(3 \mathrm{H}, \mathrm{s}, \mathrm{OMe}), 5.05-5.14(5 \mathrm{H}$, m, H-9, H-9', OH), 5.93-6.07 (2H, m, H-8, H-8'), $6.92(1 \mathrm{H}$, $\mathrm{d}, J=7 \mathrm{~Hz}, \mathrm{Ar}-\mathrm{H}), 6.97(1 \mathrm{H}, \mathrm{d}, J=8 \mathrm{~Hz}, \mathrm{Ar}-\mathrm{H}), 7.04$ $7.08(2 \mathrm{H}, \mathrm{m}, \mathrm{Ar}-\mathrm{H}), 7.24-7.31(2 \mathrm{H}, \mathrm{m}, \mathrm{Ar}-\mathrm{H}) .{ }^{13} \mathrm{C}-\mathrm{NMR}$ $\left(100 \mathrm{MHz}, \mathrm{CDCl}_{3}\right): \delta 34.5(\mathrm{C}-7), 39.6\left(\mathrm{C}-7^{\prime}\right), 55.8(\mathrm{OMe})$, $111.2\left(\mathrm{C}-3^{\prime}\right), 115.7\left(\mathrm{C}-4^{\prime}\right), 115.8$ (C-9), $116.1\left(\mathrm{C}-9^{\prime}\right), 128.0$ $\left(\mathrm{C}-1^{\prime}\right), 128.1$ (C-6), 129.0 (C-3), 129.2 (C-1), 130.0 (C-5), 130.4 (C-6'), 130.7 (C-2), $132.4\left(\mathrm{C}-5^{\prime}\right), 136.7$ (C-8), 138.0 $\left(\mathrm{C}-8^{\prime}\right), 151.0\left(\mathrm{C}-2^{\prime}\right), 157.2(\mathrm{C}-4)$. The ethanol extract of Magnolia officinalis contained 16.6\% 4-O-methylhonokiol, followed by $16.5 \%$ honokiol and $12.9 \%$ magnolol, and $42-45 \%$ others.

\section{Passive avoidance performance test}

The passive avoidance performance test is widely accepted as a simple and rapid method for memory testing [24]. The passive avoidance response was determined using a 'step-through' apparatus (Med Associates Inc., Vermont, USA) that consisted of an illuminated and a dark compartment (each of dimensions $20.3 \times 15.9 \times 21.3 \mathrm{~cm}$ ) adjoining each other through a small gate with a grid floor, $3.175-\mathrm{mm}$ stainless steel rod set $8 \mathrm{~mm}$ apart. On a training trial, the ICR mice were placed in the illuminated compartment facing away from the dark compartment. When the mice moved completely into the dark compartment, it received an electric shock $(1 \mathrm{~mA}, 3 \mathrm{~s}$ duration). Then, the mice were returned to their home cage. Twenty-four hours later after the training trial, the 
Fig. 1 Chemical structure of 4-O-methylhonokiol (a) and experimental scheme (b)
A

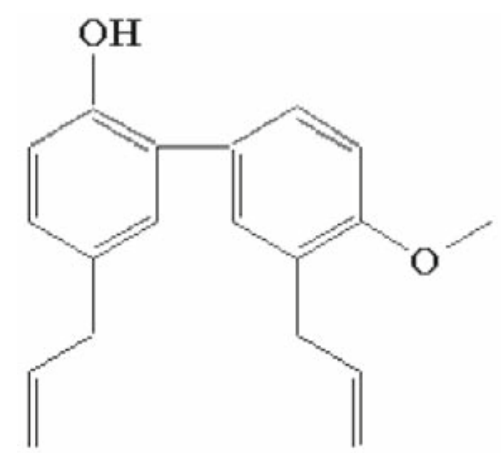

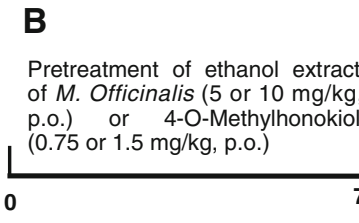

B mice were placed in the illuminated compartment and the latency period to enter the dark compartment defined as 'retention.' The time when the mice entered the dark compartment was recorded and described as step-through latency. Scopolamine $(1 \mathrm{mg} / \mathrm{kg})$ was injected intraperitoneally (i.p.) into mice $30 \mathrm{~min}$ before the retention trial. The retention trials were set at a limit of $180 \mathrm{~s}$ of cut-off time.

\section{Water maze test}

The water maze test is a widely accepted method for memory testing, and we performed this test following the method described by Morris et al. [25]. Maze testing was performed by the SMART-CS (Panlab, Barcelona, Spain) program and equipment. A circular plastic pool (height $35 \mathrm{~cm}$, diameter $100 \mathrm{~cm}$ ) was filled with milky water and kept at $22-25^{\circ} \mathrm{C}$. An escape platform (height $14.5 \mathrm{~cm}$, diameter $4.5 \mathrm{~cm}$ ) was submerged $0.5-1 \mathrm{~cm}$ below the surface of the water in position. On training trials, the mice were placed in a pool of water and allowed to remain on the platform for $10 \mathrm{~s}$, and then returned to the home cage. The mice that did not find the platform within $60 \mathrm{~s}$ were placed on the platform for $10 \mathrm{~s}$. Twenty-four hours after the last training trial (six training trials, 2 times/day for 3 days), the mice were given the test trial. Scopolamine $(1 \mathrm{mg} / \mathrm{kg}$, i.p.) was injected into mice $30 \mathrm{~min}$ before the test trial. They were allowed to swim until they discovered the escape platform. The escape latency, escape distance, swimming speed, and swimming pattern of each mouse was monitored by a camera above the center of the pool connected to the SMART-LD program (Panlab, Barcelona, Spain).
AChE activity assay

After behavior testing, the animals were perfused with PBS under inhaled chloroform anesthetization. The brains were immediately collected in the same manner and frozen stored at $-20^{\circ} \mathrm{C}$, and separated into cortical and hippocampal regions. Brain tissues were homogenized with PBS and lyzed by $60 \mathrm{~min}$ of incubation on ice. The lysate was centrifuged at 15,000 rpm for $15 \mathrm{~min}$ and the supernatant was used for the assays. AChE activity was determined by Ellman's method [26]. Briefly, $5 \mu$ l of sample was mixed with $200 \mu \mathrm{l}$ of reaction buffer $(0.5 \mathrm{mM}$ PBS pH 7.4) containing $0.02 \%$ DTNB (5,5'-dithio-bis-2-nitrobenzoic acid), $0.02 \%$ acetylcholine, and $0.1 \mathrm{mM}$ isoOMPA (tetraisopropyl pyrophosphoramide). The activity of the enzyme was determined after $5 \mathrm{~min}$ of incubation at $37^{\circ} \mathrm{C}$ and stopped with $1 \mathrm{mM} \mathrm{BW} 284 \mathrm{c} 51$, a potent selective inhibitor of AChE. The reaction mixture was converted to yellow color. The optical density was measured at $405 \mathrm{~nm}$ and then expressed as units of the quantity $(\mu \mathrm{M})$ of the acetylcholine that were hydrolyzed to thiocholine per $1 \mathrm{~min}$ per mg. Specific activity was standardized by the amount $(\mathrm{mg})$ of protein of the sample $(\mu \mathrm{M} / \mathrm{min} / \mathrm{mg}$ protein).

To test the in vitro AChE activity, the whole mouse brain was homogenized in a glass Teflon homogenizer containing ten volumes of homogenization buffer $(12.5 \mathrm{mM}$ sodium phosphate buffer, $\mathrm{pH} 7.0,400 \mathrm{mM} \mathrm{NaCl}$ ) and then centrifuged at $1,000 \times g$ for $10 \mathrm{~min}$ at $4^{\circ} \mathrm{C}$. The supernatant was used as an enzyme source for the assay. Aliquots of diluted 4-O-methylhonokiol were then mixed with reaction buffer and reacted at room temperature for $5 \mathrm{~min}$ and the activity was determined by the same method as described above. The concentrations of 4-O-methylhonokiol required to 
inhibit AChE activity by $50 \%$ ( $\left.\mathrm{IC}_{50}\right)$ were calculated using enzyme inhibition dose response curves. Tacrine was used as a positive control.

\section{Statistics}

The data were analyzed using GraphPad Prism 4 software (Version 4.03, GraphPad Software, Inc.). The data are presented as mean \pm standard error (SE). The homogeneity of variances was assessed using a Bartlett test. If variances were homogeneous, differences between groups and treatment were assessed by one-way or two-way analysis of variance (ANOVA). If the $P$-value in the ANOVA test was significant, the differences between pairs of means were assessed by Dunnet's test. One-way ANOVA was used to analyze data for AChE, while data obtained from the water Morris maze (swimming distance, escape latency, and average speed) were analyzed using two-way ANOVA. When variances were not homogeneous, the Kruskal-Wallis test was used to assess differences between groups for nonparametric analyses. Data from the step-through avoidance test (latency) were analyzed using the nonparametric tests mentioned above, followed by Dunnet's test. A value of $P<0.05$ was considered to be statistically significant.

\section{Results}

Effect of the ethanol extract of Magnolia officinalis and 4-O-methylhonokiol on the memory impairment induced by scopolamine

Escape latency (s) of animals treated with scopolamine ( $1 \mathrm{mg} / \mathrm{kg}$, i.p.) was decreased $(12 \pm 5.5 \mathrm{~s}, P<0.01)$ in comparison with the control group ( $28 \pm 7.3 \mathrm{~s})$, indicating that scopolamine induced memory impairment. On the other hand, the escape latency of animals pretreated with 5 or $10 \mathrm{mg} / \mathrm{kg}$ of ethanol extract of Magnolia officinalis for 1 week showed significant preventive effect on memory impairment compared to that of scopolamine-treated animals $(24 \pm 7.1 \mathrm{~s}, \quad P>0.05$ or $19 \pm 6.1 \mathrm{~s}, \quad P<0.05)$ (Fig. 2a). Tacrine (3 mg/kg) also showed a significant preventive effect against scopolamine-induced memory impairment $(25 \pm 1.9 \mathrm{~s}, P>0.05)$. The escape latency of animals administered with 0.75 or $1.5 \mathrm{mg} / \mathrm{kg} 4-O$-methylhonokiol was approximately 2-3 times longer than that of scopolamine-treated animals, and showed significant preventive effect on memory impairment $(28 \pm 1.8 \mathrm{~s}$, $P<0.01$ or $33 \pm 8.7$ s, $P<0.01$ ) (Fig. 2b).

To further examine the memory-enhancing activity of the ethanol extract of Magnolia officinalis and 4-O-methylhonokiol, we determined the improvement of the spatial memory function of these compounds using the Morris water maze. The mice were pretreated continuously with the ethanol extract of Magnolia officinalis $(5$ or $10 \mathrm{mg} / \mathrm{kg}$ into drinking water) and 4- $O$-methylhonokiol $(0.75$ or $1.5 \mathrm{mg} / \mathrm{kg}$ into drinking water) for 1 week, and then the animals were given the training trial. After finishing the training trial for 3 days ( 2 times/day, six times training), scopolamine ( $1 \mathrm{mg} / \mathrm{kg}$, i.p.) was then injected into the mice to induce memory impairment. Two-way ANOVA revealed an effect of the number of days $\left(F_{3,144}=6.981\right.$, $P=0.0002)$ and the treated groups $\left(F_{3,144}=6.956\right.$, $P=0.0002)$ on the escape latency, and an effect of the number of days $\left(F_{3}, 144=6.254, P<0.0001\right)$ and the treated groups $\left(F_{3,144}=9.423, P=0.0005\right)$ on the escape distance.

The escape latency on the next day of training to the platform was about $450 \pm 127 \mathrm{~cm}$ and $19 \pm 3$ s. Scopolamine-treated mice arrived slower at the location of the platform compared to the controls $(885 \pm 47 \mathrm{~cm}$, $P<0.05 ; 42 \pm 2 \mathrm{~s}, P<0.05)$. The escape latency of animals pretreated with 5 or $10 \mathrm{mg} / \mathrm{kg}$ ethanol extract of Magnolia officinalis for 1 week showed a memoryenhancing effect. The escape latency of animals pretreated with 5 or $10 \mathrm{mg} / \mathrm{kg}$ ethanol extract of Magnolia officinalis for 1 week and subsequently treated with scopolamine was shown to be approximately 2.5 or 2.4 times shorter (354 $\pm 40 \mathrm{~cm}, \quad P<0.05 ; \quad 16 \pm 3 \mathrm{~s}, \quad P<0.05 \quad$ or $361 \pm 50 \mathrm{~cm}, P<0.05 ; 17 \pm 2 \mathrm{~s}, P<0.05)$ than that of scopolamine-treated animals determined at 4 day after the training trial (Fig. 3a).

There was also shown to be a significant memoryimproving effect by the treatment with 4- $\mathrm{O}$-methylhonokiol. Elevated escape latency and escape distance by scopolamine was inhibited by the time (third and fourth day) and treatment $(1.5 \mathrm{mg} / \mathrm{kg})$. An amount of $1.5 \mathrm{mg} / \mathrm{kg}$ of 4-O-methylhonokiol significantly reduced the escape latency (s) $\left(F_{3,39}=5.983, P<0.05\right.$ and $P<0.01$ at the third and fourth days after training, respectively) and distance $(\mathrm{cm})\left(F_{3,39}=4.93, P<0.05\right.$ and $P<0.01$ at the third and fourth days after training, respectively) (Fig. 3b). The average speed was not affected by any of the treatments during all days of the evaluation (data not shown).

Effect of the ethanol extract of Magnolia officinalis and 4-O-methylhonokiol on the activities of AChE induced by scopolamine

In animals treated with scopolamine ( $1 \mathrm{mg} / \mathrm{kg}$, i.p.), the AChE activity was significantly increased in comparison with the control group, and in animals pretreated with the ethanol extract of Magnolia officinalis (5 or $10 \mathrm{mg} / \mathrm{kg}$ ) for 1 week and subsequently treated with scopolamine $(1 \mathrm{mg} /$ $\mathrm{kg}$, i.p.), the AChE activity was significantly $(P<0.05)$ 
Fig. 2 Inhibitory effect of the ethanol extract of Magnolia officinalis (a) and 4-Omethylhonokiol (b) on memory impairment induced by scopolamine in the passive avoidance test. Mice were administered the ethanol extract of Magnolia officinalis at 5.0 and $10.0 \mathrm{mg} / \mathrm{kg}$ and $4-O$ methylhonokiol at 0.75 and $1.5 \mathrm{mg} / \mathrm{kg}$ for 1 week into drinking water, and then the training trial was given on the last day. After $24 \mathrm{~h}$, the passive avoidance test was performed. Scopolamine (i.p., $1 \mathrm{mg} / \mathrm{kg}$ ) was treated $30 \mathrm{~min}$ before the test trial as a positive control. Each value is mean \pm standard error (SE) from ten animals. ${ }^{\#} P<0.05$ showed a significant difference compared with the controls. $* P<0.05$ showed a significant difference compared with the scopolamine-treated controls
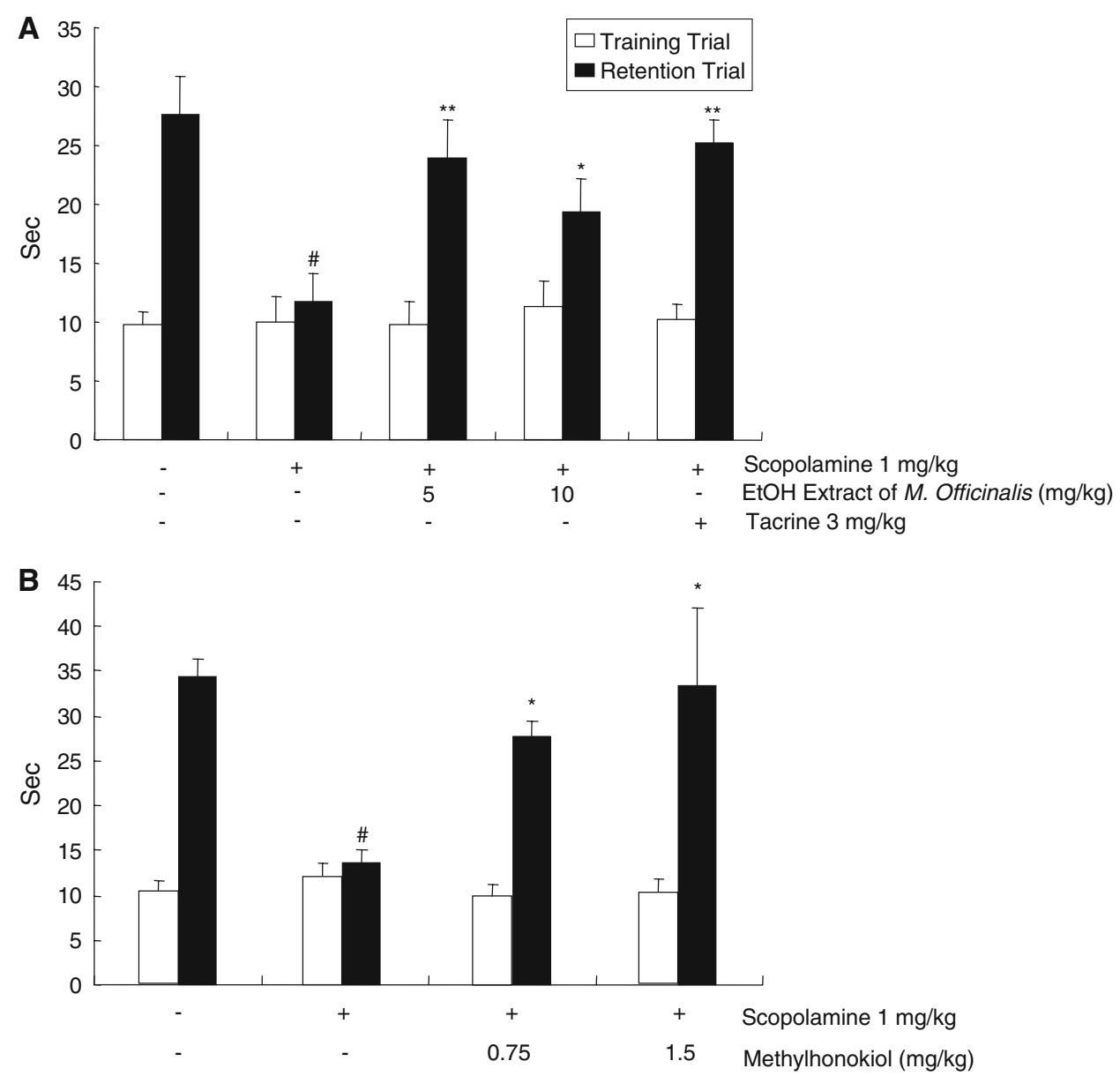

suppressed in both the hippocampus and cortex in a dosedependent manner (Fig. 4a). In animals pretreated with 4$O$-methylhonokiol $(0.75$ or $1.5 \mathrm{mg} / \mathrm{kg})$, the AChE activity was also significantly $(P<0.05)$ suppressed in the hippocampus and cortex in a dose-dependent manner (Fig. 4b). By in vitro testing, 4- $O$-methylhonokiol also inhibited AChE activity in a concentration $(1 \mathrm{nM}-100 \mu \mathrm{M})$-dependent manner, with $\mathrm{IC}_{50}$ values of $12 \mathrm{nM}$. The $\mathrm{IC}_{50}$ value of tacrine (positive control) was $135.4 \mathrm{nM}$.

\section{Discussion}

Alzheimer's disease (AD) is a progressive and eventually fatal disease of the brain, and it is the cause of more than $50 \%$ of dementia patients developing in the population older than 60 years of age [27-30]. A deficiency in acetylcholine is probably the single most common cause of declining memory [20]. AChE modulates acetylcholine to proper levels by degradation, thus, excessive AChE activity leads to constant acetylcholine deficiency, causing memory and cognitive impairments in AD [16]. Currently, AChE inhibitors (AChEI) are the first group of drugs for
AD treatment. Several AChEI have been approved by the FDA for the treatment of AD, such as tacrine $\left(\right.$ Cognex $\left.{ }^{\circledR}\right)$, donepezil $\left(\right.$ Aricept $\left.^{\circledR}\right)$, rivastigmine $\left(\right.$ Exelon $\left.^{\circledR}\right)$, and galantamine $\left(\right.$ Reminyl ${ }^{\circledR}$ ) [10]. However, these drugs have limitations in their usage, such as their short half-lives and excessive side effects caused by the activation of peripheral cholinergic systems, as well as hepatotoxicity [8, 9, 11]. Thus, a complementary therapeutic strategy is required. Neuroprotective and/or cognition-enhancing properties of natural products and their components using different animal models have been suggested as alternative therapies in several studies [12-18].

In this study, the ethanol extract of Magnolia officinalis and its major ingredient, 4- $O$-methylhonokiol, recovered the memory impairment induced by scopolamine, and its effect may be related to the ability of AChE inhibition. The step-through latency, which was reduced by scopolamine treatment, was recovered to $60-70 \%$ of the vehicle-treated control group. The Morris water maze learning task was used to assess hippocampal-dependent spatial learning ability [25, 31] and long-term memory [25]. Impairment in the long-term memory was observed in the scopolaminetreated group. However, the ethanol extract of Magnolia 

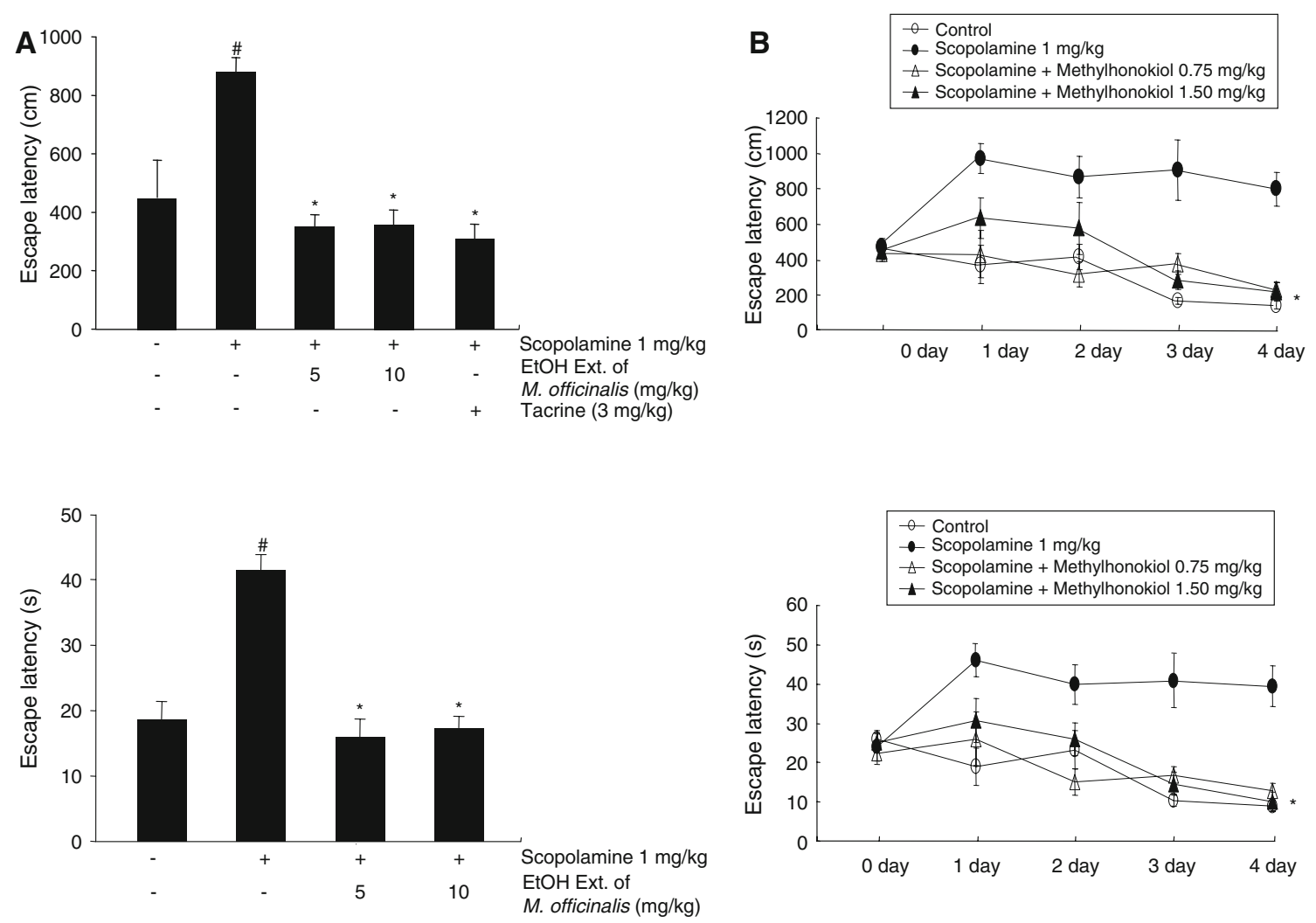

Fig. 3 Inhibitory effect of the ethanol extract of Magnolia officinalis (a) and 4-O-methylhonokiol (b) on memory impairment induced by scopolamine in the water maze test. Mice were administered the ethanol extract of Magnolia officinalis at 5.0 and $10.0 \mathrm{mg} / \mathrm{kg}$ and $4-$ $O$-methylhonokiol at 0.75 and $1.5 \mathrm{mg} / \mathrm{kg}$ for 1 week into drinking water. The mice were then given training trials six times (2 times/

officinalis and 4-O-methylhonokiol also significantly shortened the escape latencies prolonged by the scopolamine treatment. At the probe trial session, the ethanol extract of Magnolia officinalis and 4-O-methylhonokiol improved the swimming time and distance within the zone of the platform to the control level. Collectively, these behavioral studies suggest that the ethanol extract of Magnolia officinalis improves the long-term memory in an amnestic mouse model induced by scopolamine treatment, and 4-O-methylhonokiol may be a major active ingredient.

To confirm the mechanism of the action of the ethanol extract of Magnolia officinalis and its major ingredient, 4$O$-methylhonokiol, their inhibitory activity on AChE was assessed in vivo. It is well known that the memoryimproving effect of the anti-amnestic effect of tacrine and donepezil is due to the inhibition of AChE in the brain. The present data showed that the ethanol extract of Magnolia officinalis and 4-O-methylhonokiol inhibited AChE activity in a dose-dependent manner in both the cortex and hippocampus. Thus, it is likely that the memory-improving effect of the ethanol extract of Magnolia officinalis and 4-O-methylhonokiol may be, at least in part, mediated by day), and the test was performed $24 \mathrm{~h}$ after the last training trial. Scopolamine (i.p., $1 \mathrm{mg} / \mathrm{kg}$ ), as a positive control, was treated $10 \mathrm{~min}$ before the first test trial, as shown in the Fig. 1b. Each value is the mean $\pm \mathrm{SE}$ from ten animals. ${ }^{\#} P<0.05$ showed a significant difference compared with the controls. ${ }^{*} P<0.05$ showed a significant difference compared with the scopolamine-treated controls

the AChE inhibition. AChEI, such as tacrine and donepezil, causes severe hepatic toxicity, nausea, vomiting, etc., so these drugs must be used carefully. The efficacy of the ethanol extract of Magnolia officinalis and 4-O-methylhonokiol is superior compared with conventional drugs such as tacrine (Table 1). In the present study, we found that 5 or $10 \mathrm{mg} / \mathrm{kg}$ of ethanol extract of Magnolia officinalis or 0.75 or $1.5 \mathrm{mg} / \mathrm{kg}$ of $4-O$-methylhonokiol has a similar inhibitory effect to $3 \mathrm{mg} / \mathrm{kg}$ tacrine on scopolamine-induced memory impairment as well as the inhibition of AChE activity in vivo. The inhibitory effect on the AChE activity may be related to the inhibitory effect of 4-O-methylhonokiol on the expression of AChE. We observed that the elevated expression of AChE by scopolamine in both the cortex and hippocampus was decreased by the treatment with 4- $O$-methylhonokiol (data not shown). In the in vivo study, however, we did not observe clear dose-dependent prevention on the memory impairment. These unexpected data (similar dose effects) may be caused by the non differential effect of 4-Omethylhonokiol by these two doses with only two times the difference, thus, additional increased or decreased doses 

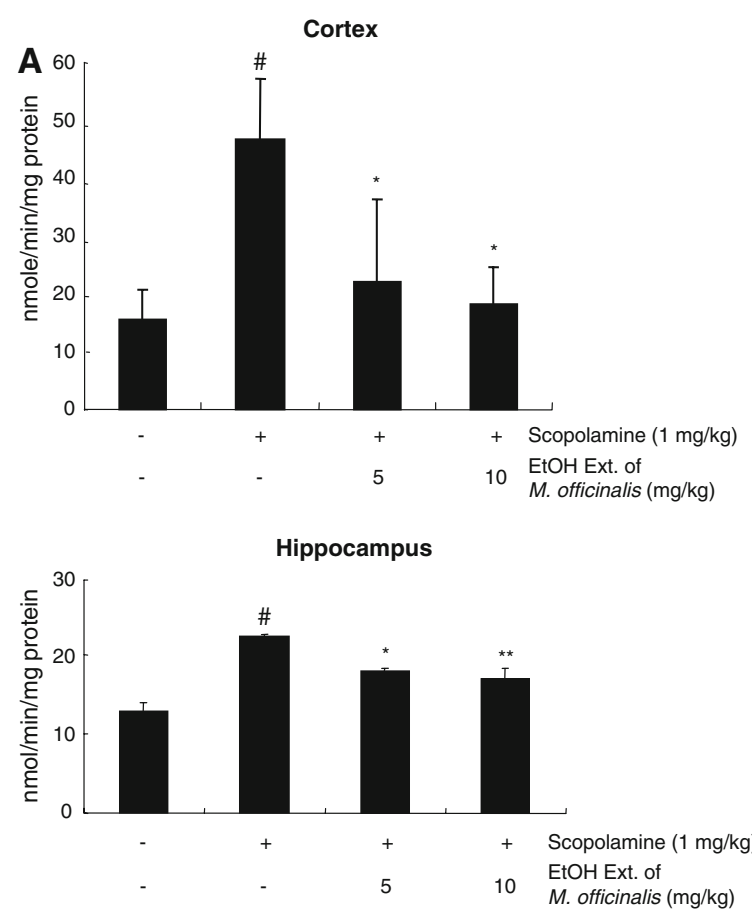

Fig. 4 Inhibitory effect of the ethanol extract of Magnolia officinalis (a) and 4-O-methylhonokiol (b) on the AChE activity in the cortex and hippocampus of scopolamine-induced mice. Mice were treated with the ethanol extract of Magnolia officinalis (5 and $10 \mathrm{mg} / \mathrm{kg}$ ) and 4-O-methylhonokiol $(0.75$ and $1.5 \mathrm{mg} / \mathrm{kg})$ for 1 week into drinking

Table 1 Inhibitory activities of acetylcholinesterase (AChE)

\begin{tabular}{llr}
\hline Compound & Concentration & Inhibition (\%) \\
\hline 4-O-methylhonokiol & $0.1 \mathrm{nM}$ & $0.4 \pm 0.1$ \\
& $1 \mathrm{nM}$ & $10.43 \pm 1.43$ \\
$10 \mathrm{nM}$ & $47.4 \pm 2.54$ \\
$100 \mathrm{nM}$ & $68.11 \pm 7.64$ \\
$1 \mu \mathrm{M}$ & $78.11 \pm 4.34$ \\
$10 \mu \mathrm{M}$ & $84.15 \pm 2.60$ \\
$1 \mathrm{nM}$ & $1.14 \pm 1.24$ \\
Tacrine & $10 \mathrm{nM}$ & $9.62 \pm 2.32$ \\
& $100 \mathrm{nM}$ & $46.54 \pm 3.86$ \\
$1 \mu \mathrm{M}$ & $54.71 \pm 7.74$ \\
$10 \mu \mathrm{M}$ & $61.41 \pm 2.94$ \\
$100 \mu \mathrm{M}$ & $59.97 \pm 5.31$ \\
\hline
\end{tabular}

Efficacy of inhibition was expressed as percent inhibition versus the control values $(100 \%)$. Values represent mean $\pm \mathrm{SD}(n=5)$

could be tested in further studies. We are currently undertaking another investigation using $\mathrm{AD}$ transgenic mice with three different doses with three times the difference among the dosing, since the present memory prevention effects were likely to be saturated, and the effect was similar to the effect of tacrine. In in vitro acetylcholine esterase, 4- $O$-methylhonokiol $\left(\mathrm{IC}_{50}: 12 \mathrm{nM}\right)$
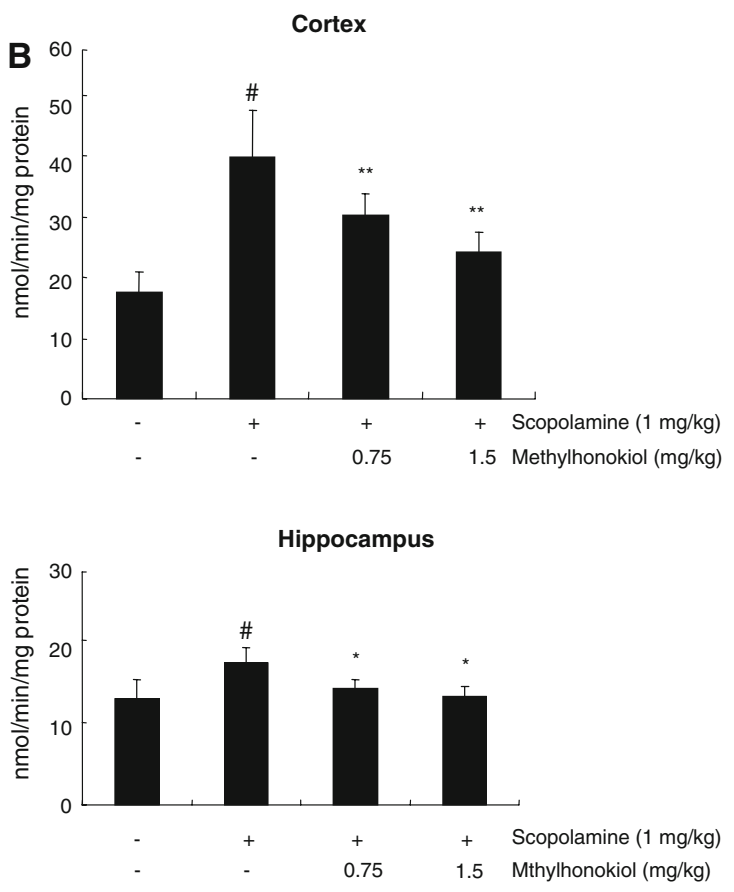

water, and then the AChE activity was measured. Each value is the mean $\pm \mathrm{SE}$ from ten animals. ${ }^{\#} P<0.05$ showed a significant difference compared with the controls. ${ }^{*} P<0.05$ showed a significant difference compared with the scopolamine-treated controls

showed more than ten times stronger inhibitory effect than tacrine $\left(\mathrm{IC}_{50}: 135.4 \mathrm{nM}\right)$. Moreover, the ethanol extract of Magnolia officinalis and 4-O-methylhonokiol originate from a natural plant, and, thus, side effects could be relatively smaller. In fact, 4-week oral treatment (up to $300 \mathrm{mg} / \mathrm{kg}$ ) of the ethanol extract of Magnolia officinalis to mice and rats did not show any toxicities in the liver, kidney, intestine, or cardiovascular and central nervous systems, and the animals did not have any high cholinergic symptoms (data not shown). Similar effects of other ingredients isolated from Magnolia officinalis, such as honokiol and magnolol, were reported to increase acetylcholine release in freely moving rats, and these effects may be related to the inhibitory effects on the AChE activity $[20,32]$. Therefore, from the above behavioral and biochemical data, it can be concluded that the ethanol extract of Magnolia officinalis has an ability to improve or ameliorate spatial long-term memory impairment, in part, via enhancement of the cholinergic nervous system, and 4-O-methylhonokiol may be one of major components of the memory-improving effect of Magnolia officinalis. It is also noteworthy that cognition-enhancing agents activate cholinergic transmission via an agonistic or antagonistic effect on $\mathrm{GABA}_{\mathrm{A}} /$ benzodiazepine receptor [33-35], and $\mathrm{GABA}_{A} /$ benzodiazepine receptor complex 
controls acetylcholine release [36]. We previously found that obovatol, a similar compound isolated from Magnolia officinalis, has high affinity of $\mathrm{GABA}_{\mathrm{A}}$ /benzodiazepine receptor [23]. Therefore, it can also be speculated that the $\mathrm{GABA}_{\mathrm{A}} /$ benzodiazepine receptor ligand properties of 4-Omethylhonokiol may also be related to the ameliorating effects on scopolamine-induced memory impairment. Further studies are needed to clarify these points. We are currently attempting to identify the mechanisms of the interactions between 4-O-methylhonokiol and $\mathrm{GABA}_{\mathrm{A}} /$ benzodiazepine receptors. Taken together, these data suggest that the ethanol extract of Magnolia officinalis and 4$O$-methylhonokiol may be useful leading compounds in anti-AD drug development.

Acknowledgments This work was supported by a grant (KRF2005-005-J15001) from the Korea Research Foundation (MOEHRD, Basic Research Promotion Fund) and by the Research Grant of Bioland Ltd. (2007-2008).

Open Access This article is distributed under the terms of the Creative Commons Attribution Noncommercial License which permits any noncommercial use, distribution, and reproduction in any medium, provided the original author(s) and source are credited.

\section{References}

1. Abramov AY, Canevari L, Duchen MR (2003) Changes in intracellular calcium and glutathione in astrocytes as the primary mechanism of amyloid neurotoxicity. J Neurosci 15:5088-5095

2. Butterfield DA (1997) Beta-amyloid-associated free radical oxidative stress and neurotoxicity: implications for Alzheimer's disease. Chem Res Toxicol 10:495-506

3. Ho PI, Collins SC, Dhitavat S, Ortiz D, Ashline D, Rogers E, Shea TB (2001) Homocysteine potentiates beta-amyloid neurotoxicity: role of oxidative stress. J Neurochem 78:249-253

4. Parks JK, Smith TS, Trimmer PA, Bennett JP Jr, Parker WD Jr (2001) Neurotoxic Abeta peptides increase oxidative stress in vivo through NMDA-receptor and nitric-oxide-synthase mechanisms, and inhibit complex IV activity and induce a mitochondrial permeability transition in vitro. J Neurochem 76:1050-1056

5. Pappolla MA, Chyan YJ, Omar RA, Hsiao K, Perry G, Smith MA, Bozner P (1998) Evidence of oxidative stress and in vivo neurotoxicity of beta-amyloid in a transgenic mouse model of Alzheimer's disease: a chronic oxidative paradigm for testing antioxidant therapies in vivo. Am J Pathol 152:871-877

6. Namba T, Nolte CT, Jackrel J, Grob D (1971) Poisoning due to organophosphate insecticides. Acute and chronic manifestations. Am J Med 50:475-492

7. Ellis JM (2005) Cholinesterase inhibitors in the treatment of dementia. J Am Osteopath Assoc 105:145-158

8. Farlow M, Gracon SI, Hershey LA, Lewis KW, Sadowsky CH, Dolan-Ureno J (1992) A controlled trial of tacrine in Alzheimer's disease. The Tacrine Study Group. JAMA 268:2523-2529

9. Knapp MJ, Knopman DS, Solomon PR, Pendlebury WW, Davis CS, Gracon SI (1994) A 30-week randomized controlled trial of high-dose tacrine in patients with Alzheimer's disease. The Tacrine Study Group. JAMA 271:985-991
10. Lahiri DK, Farlow MR, Grieg NH, Sambamurti K (2002) Current drug targets for Alzheimer's disease treatment. Drug Dev Res $56: 267-281$

11. Rogers SL, Farlow MR, Doody RS, Mohs R, Friedhoff LT (1998) A 24-week, double-blind, placebo-controlled trial of donepezil in patients with Alzheimer's disease. Donepezil Study Group. Neurology 50:136-145

12. Hatip-Al-Khatib I, Egashira N, Mishima K, Iwasaki K, Iwasaki K, Kurauchi K, Inui K, Ikeda T, Fujiwara M (2004) Determination of the effectiveness of components of the herbal medicine Toki-Shakuyaku-San and fractions of Angelica acutiloba in improving the scopolamine-induced impairment of rat's spatial cognition in eight-armed radial maze test. J Pharmacol Sci 96:3341

13. Kang SY, Lee KY, Park MJ, Kim YC, Markelonis GJ, Oh TH, Kim YC (2003) Decursin from Angelica gigas mitigates amnesia induced by scopolamine in mice. Neurobiol Learn Mem 79:1118

14. Kang SY, Lee KY, Koo KA, Yoon JS, Lim SW, Kim YC, Sung SH (2005) ESP-102, a standardized combined extract of Angelica gigas, Saururus chinensis and Schizandra chinensis, significantly improved scopolamine-induced memory impairment in mice. Life Sci 76:1691-1705

15. Houghton PJ, Agbedahunsi JM, Adegbulugbe A (2004) Choline esterase inhibitory properties of alkaloids from two Nigerian Crinum species. Phytochemistry 65:2893-2896

16. Yamada N, Hattori A, Hayashi T, Nishikawa T, Fukuda H, Fujino $\mathrm{T}$ (2004) Improvement of scopolamine-induced memory impairment by Z-ajoene in the water maze in mice. Pharmacol Biochem Behav 78:787-791

17. Yan JJ, Kim DH, Moon YS, Jung JS, Ahn EM, Baek NI, Song DK (2004) Protection against beta-amyloid peptide-induced memory impairment with long-term administration of extract of Angelica gigas or decursinol in mice. Prog Neuropsychopharmacol Biol Psychiatry 28:25-30

18. Yu MS, Leung SK, Lai SW, Che CM, Zee SY, So KF, Yuen WH, Chang RC (2005) Neuroprotective effects of anti-aging oriental medicine Lycium barbarum against beta-amyloid peptide neurotoxicity. Exp Gerontol 40:716-727

19. Song WZ, Cui JF, Zhang GD (1989) Studies on the medicinal plants of Magnoliaceae tu-hou-po of Manglietia. Yao Xue Xue Bao 24:295-299

20. Tsai TH, Westly J, Lee TF, Chen CF, Wang LCH (1995) Effects of honokiol and magnolol on acetylcholine release from rat hippocampal slices. Planta Med 61:477-479

21. Yamazaki R, Sugatani J, Fujii I, Kuroyanagi M, Umehara K, Ueno A, Suzuki Y, Miwa M (1994) Development of a novel method for determination of acetyl-CoA:1-alkyl-sn-glycero-3phosphocholine acetyltransferase activity and its application to screening for acetyltransferase inhibitors. Inhibition by magnolol and honokiol from Magnoliae cortex. Biochem Pharmacol 47:995-1006

22. Fukuyama Y, Otoshi Y, Miyoshi K, Nakamura K, Kodama M, Nagasawa M, Hasegawa T, Okazaki H, Sugawara M (1992) Neurotrophic sesquiterpene-neolignans from Magnolia obovata: structure and neurotrophic activity. Tetrahedron 48:377-392

23. Seo JJ, Lee SH, Lee YS, Kwon BM, Ma Y, Hwang BY, Hong JT, Oh KW (2007) Anxiolytic-like effects of obovatol isolated from Magnolia obovata: involvement of GABA/benzodiazepine receptors complex. Prog Neuropsychopharmacol Biol Psychiatry 31:1363-1369

24. Ogren SO (1985) Evidence for a role of brain serotonergic neurotransmission in avoidance learning. Acta Physiol Scand Suppl 544:1-71

25. Morris R (1984) Developments of a water-maze procedure for studying spatial learning in the rat. J Neurosci Methods 11:47-60 
26. Ellman GL, Courtney KD, Andres V Jr, Feather-Stone RM (1961) A new and rapid colorimetric determination of acetylcholinesterase activity. Biochem Pharmacol 7:88-95

27. Checler F (1995) Processing of the beta-amyloid precursor protein and its regulation in Alzheimer's disease. J Neurochem 65:1431-1444

28. Hardy J (1997) Amyloid, the presenilins and Alzheimer's disease. Trends Neurosci 20:154-159

29. Hardy JA, Higgins GA (1992) Alzheimer's disease: the amyloid cascade hypothesis. Science 256:184-185

30. Hwang DY, Chae KR, Kang TS, Hwang JH, Lim CH, Kang HK, Goo JS, Lee MR, Lim HJ, Min SH, Cho JY, Hong JT, Song CW, Paik SG, Cho JS, Kim YK (2002) Alterations in behavior, amyloid beta-42, caspase-3, and Cox-2 in mutant PS2 transgenic mouse model of Alzheimer's disease. FASEB J 16:805-813

31. Barnes CA, Danysz W, Parsons CG (1996) Effects of the uncompetitive NMDA receptor antagonist memantine on hippocampal long-term potentiation, short-term exploratory modulation and spatial memory in awake, freely moving rats. Eur $\mathrm{J}$ Neurosci 8:565-571

32. Hou YC, Chao PD, Chen SY (2000) Honokiol and magnolol increased hippocampal acetylcholine release in freely-moving rats. Am J Chin Med 28:379-384

33. Lal H, Kumar B, Forster MJ (1988) Enhancement of learning and memory in mice by a benzodiazepine antagonist. FASEB J 2:2707-2711

34. Preston GC, Ward C, Lines CR, Poppleton P, Haigh JR, Traub M (1989) Scopolamine and benzodiazepine models of dementia: cross-reversals by Ro 15-1788 and physostigmine. Psychopharmacology (Berl) 98:487-494

35. Smythe JW, Murphy D, Costall B (1996) Benzodiazepine receptor stimulation blocks scopolamine-induced learning impairments in a water maze task. Brain Res Bull 41:299-304

36. Vazquez J, Baghdoyan HA (2003) Muscarinic and $\mathrm{GABA}_{\mathrm{A}}$ receptors modulate acetylcholine release in feline basal forebrain. Eur J Neurosci 17:249-259 